\title{
TRADUÇÃO, ACASO E AUTOBIOGRAFIA EM JACQUES DERRIDA $^{1}$
}

\section{Paula Glenadel}

(...) era preciso contar com essa "cultura" para ali traduzir, atrair, seduzir isso mesmo, o "alhures", para o qual eu mesmo era antecipadamente ex-portado, a saber, o "alhures" desse totalmente outro com o qual tive de preservar, para me preservar, mas também para me preservar dele, como de uma temível promessa, uma espécie de relação sem relação, um se preservando do outro na espera sem horizonte de uma língua que apenas sabe fazer-se esperar.

\section{Jacques Derrida, Le Monolinguisme de l'autre $^{2}$}

A tradução, isto é, uma variedade de sentidos relacionados àquilo que se costuma designar como tradução, traz consigo implicações simultaneamente teóricas e práticas para o pensamento de Jacques Derrida. Entendida como um processo de relação entre o mesmo e o outro, tal como ela aparece na leitura de Walter Benjamin realizada por ele em Torres de Babel, onde a questão principal sublinhada na tarefa do tradutor é a sobrevida do texto original enquanto fragmento de uma unidade linguística perdida o que caracteriza esta última, no mesmo movimento, como unidade linguística por reencontrar - , ela pode ser vista ao longo de sua obra no sentido da exigência de abertura ética para o outro tragicamente ausente. ${ }^{3}$ Este outro é o outro humano, certamente, o falante de outra língua, mas também o "totalmente outro", figura informe que remete a uma promessa tomada no contexto da estrutura aporética da justiça por vir.

\footnotetext{
${ }^{1}$ Parte desse texto foi apresentada em setembro de 2013, durante o XI Congresso Internacional da ABRAPT e V Congresso Internacional de Tradutores, no simpósio Poéticas da Tradução.

${ }^{2}$ Assinalo que todas as traduções do francês neste artigo foram feitas por mim, mesmo nos casos em que havia tradução das obras para o português, pois, de modo indissociável, o movimento de traduzir faz parte do meu próprio processo de escrita e de reflexão. Essa escolha não significa fazer valer minha autoria tradutória sobre (eventuais) traduções já publicadas e indica apenas que, aqui, como em outros textos que produzi, a tradução e os dilemas suscitados por ela são o ponto de partida da investigação.

${ }^{3}$ Assim, não é de se estranhar, portanto, que um dos livros onde Derrida trabalha mais intensamente a questão da justiça por vir (e da ausência/presença) seja Espectros de Marx (Paris: Galilée, 1993), em diálogo profundo com a tragédia de Hamlet, que inspira subterraneamente a reflexão do teórico Karl Marx e que será, por isso, reivindicada para a análise do seu pensamento social.
} 
Tal é o ponto visado por todos os conceitos ou, melhor dizendo, quase-conceitos derridianos, de maneira que foi se tornando cada vez mais explícita na sua escrita, de onde se explica o surgimento da expressão "virada ética", aplicada à obra de Derrida a partir dos anos 80, encontrada em muitos dos comentários sobre ela. É preciso assinalar, contudo, que o termo "virada" não é exato, uma vez que a perspectiva de abertura ética para a alteridade sempre foi uma marca do pensamento derridiano, desde os primeiros livros em que ele começou a se constituir. Juntamente, aliás, com a perspectiva autobiográfica, na medida em que sua ambígua posição de excentricidade em relação à cultura francesa da qual ele se tornou um dos mais conhecidos representantes faz com que nele, o desejo de dar voz ao outro se confunda, cada vez mais, com o seu próprio relato autobiográfico, como veremos um pouco mais adiante.

A este primeiro sentido, relativo às linhas mais fundamentais da teorização derridiana, se acrescenta o sentido da conscientização sobre a incompletude de qualquer língua, agudamente sentida nas perdas que ocorrem ao longo de todo processo de tradução, e que permite que se fale desta também em termos que evocam o luto ou a melancolia. ${ }^{4}$ Através de uma experiência de escrita, esse absoluto, que não existe, se inscreve enquanto abertura, desejo de uma língua por vir. Nesse sentido, a tradução aparece aqui, simultaneamente, como aquilo que move essa escrita e aquilo que constitui um obstáculo à sua recriação em outro idioma. Desse modo, ela constitui também o limiar do poema, se não da poesia ${ }^{5}$ e, portanto, também da prática de escrita de Derrida que, como a de Jacques Lacan, por exemplo, se afirma no corpo do significante, a tal ponto que não se pode falar de conceitos desses teóricos sem trazer junto os termos em que são colocados.

Em uma rica entrevista concedida a Aliette Armel em 2004, poucos meses antes de sua morte, para o Magazine littéraire, em que ele e Hélène Cixous discutem sobre certas afinidades existentes entre suas obras e interesses filosófico-literários, Derrida constata:

\footnotetext{
${ }^{4}$ Veja-se, por exemplo, a obra de Susana Kampff Lages: Walter Benjamin: tradução e melancolia. São Paulo: Edusp, 2002.

${ }^{5}$ Conforme a preferência de Derrida de falar da poesia através do poema, caracterizado como o ouriço protegido-desprotegido que precisa atravessar uma estrada, cena que é uma figuração da questão da tradução, mas também uma meditação pós-heideggeriana sobre as relações entre arte, natureza e técnica, que encontramos em Che cos'è la poesia (Derrida, 1992).
} 
Seríamos como dois escritores franceses que cultivam uma relação estranha ou estranhamente familiar, familiarmente estranha (unheimlich, uncanny) com a língua francesa - ao mesmo tempo mais traduzidos e mais intraduzíveis do que muitos autores franceses. Nós estaríamos mais enraizados na língua francesa do que aqueles que têm suas raízes ancestrais nessa cultura e nessa terra (Derrida \& Cixous, 2004, p. 27).

Textos como Torres de Babel, O que é uma tradução relevante, O que é a poesia, O monolinguismo do outro, entre outros, tematizam incessantemente esses aspectos da tradução, resumidos por Derrida na sua conhecida fórmula paradoxal e hiperbólica, ${ }^{6}$ a qual propõe que "Nada é intraduzível num sentido, mas em outro sentido tudo é intraduzível, a tradução é outro nome do impossível.” (Derrida, 1996, p. 103) O impossível é um dos grandes filosofemas derridianos, que ele escreve muitas vezes, conforme explica, “com um hífen entre im- e possível, para sugerir que essa palavra não é negativa no uso que faço dela. O im-possível é a condição de possibilidade do acontecimento, da hospitalidade, do dom, do perdão, da escrita" (Derrida, 2004, p. 28). A tradução, nessa apresentação pela sua face de im-possível vem, assim, juntar-se a tudo aquilo que de mais importante Derrida se propôs a pensar.

A partir, então, dessas breves indicações sobre a relevância da tradução no contexto da obra de Derrida, caberia também indicar de que modo, nele, a tradução aparece investida pelo acaso, na medida em que se liga aos jogos poético-filosóficos característicos da sua escrita que são em grande parte idiomáticos, possuindo caráter arbitrário e caprichoso e não se deixando transportar de maneira constante entre línguas, num jogo que a reflexão autobiográfica do "monolinguismo do outro" tenta acompanhar.

"Foi lhes falando de acaso e de linguagem que acreditei ter mais chances de ser pertinente, isto é, de tocar meu assunto tocando vocês" (Derrida, 1987, p. 356). Em Mes chances (onde a tradução tropeça inevitavelmente desde o título, que teria de se desdobrar, em português, em Minhas chances/Minhas sortes), texto que trabalha as ideias de "álea" e "código" na sua relação com o tratamento científico ou artístico do

\footnotetext{
${ }^{6}$ Esse hiperbolismo, que ele apresenta como contraído em ambiente escolar, nas diferentes escolas francesas por onde passou, é recorrente na sua escrita e gera, paradoxalmente em relação à própria ideia de desconstrução do eurocentrismo, um estilo "mais francês do que o francês", "mais "puramente francês' do que o exigido pela pureza dos puristas ao passo que, desde sempre, eu ataco a pureza e a purificação em geral (...)” (Derrida, 1996, p. 82).
} 
acaso e da linguagem, aparentemente saímos do plano da ética em direção a um plano, digamos, mais "descritivo" ou estrutural. Todavia, uma vez que a álea significa, por exemplo, no código jurídico, a possibilidade de lucro simultânea à de prejuízo - em suma, o risco, ${ }^{7}$ é possível ler o jogo da álea e do código como equivalente ao jogo do outro que, na sua potência de me expor imprevisivelmente, rompe o contrato, o código, dentro do qual eu, o "mesmo", poderia me acreditar protegido, abrigado. Pois, segundo Derrida, se compreendemos que a hospitalidade é "de visita e não de convite" (Derrida, 2004, p. 28), "a exposição ao outro só pode tomar a forma da im-potência" (ibidem), pelo incalculável do encontro com o outro visto como acaso, aquilo que "cai" sobre o narcisismo e o altera.

Em relação a essa aporia, a literatura, na sua condição ambivalente de código e álea, de marca iterável e de singularidade de nome próprio, manteria para nós um privilégio de "lugar do acaso e da chance/sorte" (Derrida, 1987, p. 369), nos provocando a pensar o acontecimento, uma vez que as obras literárias são performativas, elas "caem sobre nós, elas dizem ou desvelam o que cai sobre nós enquanto caem sobre nós" (ibidem). Isso explicaria sem dúvida a natureza da escrita filosófica perseguida por Derrida. Segundo Peggy Kamuf, que figura entre seus principais tradutores para o inglês, ele, através de sua escrita inventiva,

(...) manobra com a língua francesa e a solicita, pedindo-lhe que dê sempre mais sentidos a fim de deixar passar em cada frase uma pluralidade de outras frases. Nenhum texto de Derrida é simples, todos abrigam uma multidão incalculável de outros textos sob uma aparente unicidade. Que essa pluralização irredutível e inevitável caracterize qualquer escrito como a própria condição de sua legibilidade, eis o que Derrida pensou e analisou escrevendo obras teóricas na mesma medida em que são performativas (Kamuf, 2004, p. 49).

Apontando o excepcional movimento dessa escrita, que é o de "tomar frequentemente uma linguagem bem simples, até popular, familiar em seu tom e em seu ritmo, reconhecível para qualquer um que entenda o francês, para introduzir nela algo inaudito, extraordinário, e irreconhecível" (ibidem), Kamuf fala de "milagre" ao descrever essa riqueza capaz de exasperar o tradutor de Derrida, que raramente tem à sua disposição nesse trabalho o tempo suficiente para "deixar vir à mente coincidências inesperadas" (ibidem) capazes de acompanhar o seu movimento. São muitos os termos

\footnotetext{
${ }^{7}$ Conforme o dicionário HOUAISS, verbete "álea".
} 
que poderiam ser convocados para pensar esse ponto, numa ampla gama de valores: além destes, milagre e coincidências inesperadas, também se poderiam invocar os termos acaso, destino, maldição, bênção.

Em O monolinguismo do outro, Derrida apresenta sua "genealogia judaicofranco-magrebina" (Derrida, 1996, p. 133) como aquilo que move, ainda que não o explique completamente, seu desejo de escrever e de pensar, de forma que a explicitação da autobiografia apareceria aqui como imperativo de tradução e de atribuição de legibilidade a essa história plural que o coloca "en demeure" (ibidem), ou seja, obrigado a executar sem demora sua obrigação, e que faz dele um "refém" (ibidem):

Certamente, tudo o que, digamos, me interessou desde há muito tempo — em termos da escrita, do rastro, da desconstrução do falogocentrismo e "da" metafísica ocidental (que jamais, apesar do que se disse repetidamente, identifiquei como uma só coisa homogênea e vigiada por seu artigo definido no singular, tantas vezes eu disse o contrário, e de maneira tão explícita!) tudo isso não pode não ter procedido dessa estranha referência a um "alhures", cujo lugar e língua eram para mim mesmo desconhecidos ou interditos, como se eu tentasse traduzir na única língua e na única cultura franco-ocidental de que disponho, na qual fui jogado ao nascer, uma possibilidade inacessível a mim mesmo, uma fala que eu ainda não conhecia (...) (Derrida, 1996, p. 131-132).

Nessa apresentação, curiosamente, a questão de Mes chances, espraiada entre os campos da poética, da tradução e da filosofia, na sua múltipla indagação sobre as condições de recepção de uma língua alterada, tensionada, pensante, retorna em diferença: "Quais são, então, as chances de legibilidade de tal discurso sobre a ilegibilidade?" (p. 134, grifo meu).

Sobre seu percurso autobiográfico, eis a avaliação que ele faz: "Não sei se é arrogância ou modéstia pretender que essa foi, em grande medida, minha experiência, ou que isso se parece um pouco, ao menos pela dificuldade, com meu destino" (p. 111). Nesse sentido, estando "dentro e fora" da língua francesa como aponta Cixous, ${ }^{8}$ o gesto recorrente em Derrida é o de apresentar suas marcas, traços idiomáticos ou idiossincráticos como acaso, visto como "sorte", e incorporado como "benção", com todas as ambivalências presentes na tradução de chance — entre "sorte" e "chance": "A

\footnotetext{
${ }^{8}$ Nessa entrevista já referida, Cixous diz que "A passagem entre dentro e fora se encontra em tudo o que escrevo, como em todo o pensamento de Jacques Derrida” (Derrida \& Cixous, 2004, p. 25).
} 
sorte (chance) obscura, minha sorte (chance), uma graça pela qual seria preciso agradecer a não sei qual potência arcaica, é que sempre me foi mais fácil abençoar esse destino. Mais fácil, na maioria das vezes, e ainda agora, do que maldizê-lo" (p. 122).

Atualizando o eterno retorno concebido por Friedrich Nietzsche, essa espécie de duplo "sim" derridiano gera uma relação afirmativa com o mundo e seus acontecimentos, e talvez, mais do que a tão percorrida via "negativa" da desconstrução, privilegiada por muitos dos seus leitores, seja o mais profundo legado de Derrida para o seu tempo.

O aspecto da tradução ligado ao acaso introduz, assim, o elemento autobiográfico no discurso filosófico derridiano. É preciso ainda acrescentar que o gosto de Derrida pela biografia e pela autobiografia deve ser entendido, como aponta Marcos Siscar em sua reflexão baseada no jogo entre auto e oto ${ }^{9}$ cuja perfeita homofonia em francês se perde na tradução para o português,

(...) num sentido particular segundo o qual a vida não pode ser escutada se não nos sentimos "pegos pela orelha", ao mesmo tempo contrariados e à sua escuta, numa espécie de "otobiografia". A escuta da vida inteira é também de certo modo uma incursão às fronteiras da morte, isto é, ao fim, a partir do qual unicamente se poderia esperar; esperar encontrar os contornos da totalidade de uma vida inteira (Siscar, 1999, p. 475).

Essa observação faz ecoar o termo usado por Derrida no comentário de ainda há pouco sobre sua obrigação de escrita a partir da sua história plural. No livro a que ele dá nome, Demeure, o termo demeure retorna, na qualidade de leit-motiv da leitura derridiana do texto autobiográfico $O$ instante da minha morte de Maurice Blanchot, o relato de sua quase-execução, questionador das fronteiras entre ficção e testemunho. Esse termo atravessa o espaço narrativo em diversos momentos, com diferentes valores a cada ocorrência, e diz da demora, do atraso, da espera, também da morada, e da morte, enfim, através de uma leitura que recupera a estranheza da língua, através de uma escuta, como a do verso de Pierre Corneille citado por Derrida: "Sim, sem mais demora (demeure), Pelo interesse dos deuses, consinto em que ela morra (meure)" (Derrida, 1998, p. 102).

\footnotetext{
${ }^{9}$ Criado em Derrida, 1984.
} 
Demeure é mais um termo que, acionado pela escrita idiomática de Derrida, ${ }^{10} \mathrm{se}$ torna poético ou performativo, carregando em si a mesma exigência de possibilidadeimpossibilidade observada no seu pensamento sobre a tradução. Ao incorporar poeticamente (isto é, no corpo da linguagem, puxando-nos pela orelha) a vida à morte, Derrida insiste sobre o aspecto de "autobio-tanatografia" (p. 94) que a literatura pode assumir, sublinhando que a vida é simultaneamente negação e cooperação com a morte, um des-morrer, não a morada permanente da qual a morte viria nos expulsar, mas a exposição ao acaso, ou, em outras palavras, à "Hospitalidade da própria morte." (p. 52) Ele acrescenta que essa é "uma definição da escrita do desastre" (ibidem). Em última análise, podemos afirmar que, por essas características, o que chamamos de desconstrução seria também uma escrita do desastre: uma escrita que se nutre de uma forma de ser desconhecida, elegendo-a como seu destino.

Essa peculiar relação do pensamento de Derrida com a vida e a morte é complexa o suficiente para dar margem a muitos questionamentos. Reconhecendo a insistência da morte e temas afins no pensamento da desconstrução, após a morte de Jacques Derrida, num gesto de homenagem ao pensador que não exclui uma rigorosa problematização de seu discurso, ao escrever sobre o seu legado, Jacob Rogozinski aponta um traço irredutível de melancolia, que ele desenvolve de modo "ortodoxo", ou seja, tentando diferenciá-la conceitualmente do trabalho de luto, na pista de Sigmund Freud e de seus intérpretes:

(...) contestando a primazia da introjeção, ele foi necessariamente levado a privilegiar o paradigma da incorporação. De maneira mais ou menos clandestina, sem mostrar abertamente sua preferência - e, entretanto, certos motivos essenciais de seu pensamento (o dobre de finados, a cripta, o retorno, a espectralidade, e, também, vamos vê-lo, a desconstrução da Aufhebung) têm suas raízes nessa experiência, a de uma incorporação melancólica. Por mais alegre e jubilosa que ela possa parecer, haveria então uma melancolia da desconstrução, a melancolia mesma de Penélope destecendo sempre de novo seu interminável trabalho (Rogozinski, 2005, p. 26).

Se não há, efetivamente, como não concordar que o luto da metafísica é impossível, ${ }^{11}$ e muito menos, motivos para fazê-lo, essa imagem escolhida por

\footnotetext{
${ }^{10}$ É possível citar outros, como, por exemplo, o pas, ao mesmo tempo "passo" e partícula de negação, que comparece em outros momentos de suas leituras de Blanchot.

${ }^{11}$ Ainda Rogozinski: "Melancolia da desconstrução: ela confirma o impossível luto da metafísica. Se é verdade que a metafísica é a doença do Ocidente, então a incorporação melancólica seria seu remédio, seu pharmakon, tão perigoso, talvez, quanto o mal que ele pressupõe curar.” (Rogozinski, 2005, p. 39).
} 
Rogozinski contém, entretanto, algo que talvez merecesse ser mais enfatizado. A partir do que o termo demeure nos ensina, compreendemos que ao des-fazer o que havia sido feito, o campo aberto por esse trabalho de Penélope libera o espaço para tornar a fazer, indefinidamente, sem preocupação com o término ou a conclusão do trabalho, de um modo que se aproxima do des-morrer, nos significando que isso a que na nossa experiência chamamos vida não exclui a morte, e que é disso que a literatura, a filosofia, a tradução vêm nos dar notícias.

\section{Referências bibliográficas:}

DERRIDA, Jacques. Otobiographies. L'enseignement de Nietzsche et la politique du nom propre. Paris : Galilée, 1984.

. Che cos'è la poesia. In: WEBER, E. (Org.) Points de suspension. Entretiens. Paris: Galilée, 1992.

. Le monolinguisme de l'autre. Paris: Galilée, 1996.

. Demeure. Maurice Blanchot. Paris: Galilée, 1998. 1987.

Mes chances. In : Psyché, Inventions de l'autre (tome 1). Paris: Galilée,

\& CIXOUS, Hélène. Du mot à la vie. Entrevista ao Magazine Littéraire Dossier Jacques Derrida. n. 430, avril 2004.

KAMUF, Peggy. Traduire dans l'urgence. In : Magazine Littéraire - Dossier Jacques Derrida. n. 430, avril 2004.

ROGOZINSKI, Jacob. Faire part. Cryptes de Derrida. Paris: Ed. Lignes et Manifestes, 2005.

SISCAR, Marcos. La passion ingrate. In: MALLET, Marie-Louise (Org.) L'animal autobiographique. Autour de Jacques Derrida (Colloque de Cerisy 1997). Paris: Galilée, 1999. 